Authors' post-print (final draft post-refereeing)

To be published as:

Heylighen, A., Van der Linden, V., Van Steenwinkel, I. (2017). Ten questions concerning inclusive design of the built environment. Building and Environment.

Please refer to the publisher's final print version. 


\section{Ten questions concerning inclusive design of the built environment}

Abstract: In recent years, the design community has witnessed the development of several design approaches aimed at taking into account the diversity of human abilities and conditions during design. One of these approaches is inclusive design, used here as an umbrella term to cover also universal design and design for all. This article addresses some of the common questions that arise when inclusive design is considered in relation to the built environment. It discusses how inclusive design is defined and interpreted, what its relevance, implications and challenges are in relation to the built environment, how it relates to other significant design issues, and how it can be fostered in the future. This introduction to the idea of inclusive design is of interest to built environment professionals and researchers seeking a more holistic approach to the built environment. Foregrounding the diversity in human interactions with the built environment supports reflection on the human impact of design decisions. By offering diverse spatial qualities and use opportunities, inclusive design has the potential to help addressing the challenges of our diverse and ageing society in a sustainable way.

Keywords: accessibility, built environment, design for all, inclusive design, universal design, user expertise

\section{Introduction}

Several design approaches aspire to take into account the largest range of users possible during design. These approaches include, for example, universal design (UD) $[1,2,3]$, inclusive design $[4,5,6]$ and design for all [7]. Despite their different place of origin and some semantic distinctions, all these approaches share a similar purpose. In this article they will therefore be considered interchangeably 
and henceforth referred to as inclusive design. This term is chosen over the other two because it directly reflects the common ambition of these approaches to include as many people as possible.

Inclusively designed environments can offer diverse spatial qualities and opportunities for using spaces in multiple ways, by taking into account people's diverse abilities. Very telling in this respect is the work of architects Carlos Pereira or Chris Downey. Since they lost their sight, they each use their embodied knowledge of being blind to create richer architecture by incorporating shapes and materials for their multisensory potential [8]. In designing a proposal for a sea bathing facility at the Portuguese coast, for instance, Pereira chose the basin's rounded shapes for their haptic qualities and integrated seaweeds in the smaller basins for their olfactory and tactile qualities (see Fig. 1).

[insert Figure 1 about here]

Several studies suggest, however, that the adoption of inclusive design in design practice is limited so far, especially in relation to the built environment $[9,10]$. This limited adoption may relate to misconceptions existing around inclusive design [11]. Studies show that inclusive design is understood by architects and other built environment professionals in multiple ways $[10,11,12]$ : inclusive design is considered as a set of good intentions, a basic attitude that seems to be associated with accessibility and functionality; it is also considered as utopian [16], since its goal to design for everyone is impossible to reach. As a result, many architects and other built environment professionals may feel uncertain as to what exactly inclusive design entails. This suggests that there are still many challenges to address, relating to the perceptions and the practical applicability of inclusive design.

The following introduction to inclusive design is of interest to built environment professionals and researchers who want to contribute to fostering a more holistic understanding of the built environment, taking into account the diversity of human interactions with it. Inclusive design is not limited to the work of architects, as we will illustrate, but is a concern for all kinds of built environment experts (in, e.g., acoustics, indoor comfort, sustainability, urban design and planning) 
whose decisions have profound impacts on people. The next section considers ten of the common questions that arise when inclusive design is considered in relation to the built environment. Figure 2 gives an overview of the themes and questions addressed.

[insert Figure 2 about here or after the list]

- In order to shed some light on terminologies, we will start with a definitions section, providing built environment professionals and researchers with a compass to navigate different design approaches and their backgrounds. This section provides a state of the art on how inclusive design is understood (Q1) and how it distinguishes from related concepts such as design for special needs, accessible, user-centred and human-centred design (Q2).

- To offer built environment professionals and researchers insight into the 'why' and the 'why now', the relevance section explains how the notion of diversity includes all of us (Q3) and how inclusive design is of current interest in the light of participatory trends and changing demographics (Q4).

- Next, the implications and challenges section illustrates what inclusive design implies at different scales of the built environment (Q5), and discusses how its potential is currently challenged by built environments professionals' concerns about its added value (Q6) and the difficulties they face in putting inclusive design to practice (Q7).

- The subsequent section discusses how inclusive design relates to other design issues. Working with user/experts (Q8), for example, may hold the potential to tackle the perceived challenges. We also highlight the close relation with the sustainable design practices that built environment professionals are putting in place (Q9).

- The outlook section finally presents directions in which inclusive design can be fostered in the future (Q10), both in practice and education. 


\section{Ten questions (and answers) concerning inclusive design of the built environment}

\subsection{Definitions}

\section{Question 1: How is inclusive design defined and understood?}

Answer: As mentioned, architects and other built environment professionals interpret the related concepts of inclusive design, universal design and design for all in multiple ways. These different interpretations should perhaps not come as a surprise, given the ways in which these approaches are portrayed in the literature.

Inclusive design thinking emerged and developed in nations and regions across the world. Ronald Mace, an American architect using a wheelchair, is said to have coined the term universal design in 1985 to denote: "a way of designing a building or facility, at little or no extra cost, so that it is both attractive and function for all people, disabled or not" [1]. Building upon his definition, the United Nations Convention of the Rights for Persons with Disabilities (CORD) described universal design as "the design of products, environments, programmes and services to be usable by all people, to the greatest extent possible, without the need for adaptation or specialized design" [13]. In the UK, Roger Coleman "introduced the idea of Inclusive Design, arguing that needs and abilities change throughout the life-course and that by taking account of this in the design process, products, services and environments can be improved for the majority of customers in ways that are not associated with negative perceptions of age or disability" [4]. Moreover, Coleman stresses that "[t]aking these factors into account can also enhance a company's reputation for care and customer service, and its profitability without necessarily adding to costs" [4]. Accordingly, the British Design Council defined inclusive design as "a general approach to designing in which designers ensure that their products and services address the needs of the widest possible audience, irrespective of age or ability" [14]. The European Institute for Design and Disability (EIDD), for its part, advances design for all as "design for human diversity, social inclusion and equality" [7]. Its Stockholm declaration stipulates that design for all "aims to enable all people to have equal opportunities to participate in every aspect of society. To 
achieve this, the built environment, everyday objects, services, culture and information - in short, everything that is designed and made by people to be used by people - must be accessible, convenient for everyone in society to use and responsive to evolving human diversity" [7].

Differences exist in how inclusive design thinking has evolved in different contexts [15]. For instance, Clarkson and Coleman [24] depict universal design as "a discrete form of design with its own principles", which they contrast with inclusive design as "'a simple concept to help [manufacturers and retailers] see potential commercial benefits for their businesses', along with 'examples of how that concept could be applied in practice'"'. In their view, what is unique to inclusive design is that it advances the number of people who are excluded by a design as a quantifiable aspect of products and services. This notion of "design exclusion" is said to differentiate (their approach to) inclusive design from the more "aspirational" universal and inclusive design approaches by assuming as a start point that no design will work perfectly for everyone, and by making inclusive design amenable to business and industry. Yet, rather than by the place of origin, the different ways in which each of the concepts gains meaning may be explained by the people by whom and the way in which they are developed.

The similarities are more apparent than the differences, however [15]. In this respect, the following elements are particularly important in the definitions outlined above: that inclusive design is a way of designing, an approach to design; that it focuses on how design can address themes like diversity, equality, and social inclusion; that it strives towards the greatest possible application; and that the resulting design can be used by all people. In other words inclusive design can be described as an attitude to design that seeks to include as many people as possible.

Overall inclusion is thus the ideal to aspire. This does not mean, however, that inclusive design advocates are blind for the reality, in particular for the fact that in practice it is impossible to really design for everyone, that unforeseen problems always can and will arise, and the objectives of inclusive design in reality thus cannot be realized. This limitation is clearly acknowledged by several 
authors: designers should keep in mind all users "to the greatest extent possible". In principle, it is thus important not to exclude anyone a priori in the description of the target group and the actual design process. Furthermore, the impossible or the utopian is advanced as a determinative characteristic [16], "a goal toward which to strive" [17].

At the same time, however, inclusive design is also advanced as a set of specifications of what is being designed. The seven principles of universal design, for instance, read as criteria to be met by products, spaces and services: they should allow for "equitable", "flexib[le]", "simple and intuitive use", provide "perceptible information", foresee "tolerance for error", require "low physical effort", and provide "size and space for approach and use" [18]. Moreover, Elaine Ostroff [15] points out, "the term universal design has been inappropriately adopted by some architects, especially in the US, as a trendy synonym for compliance with the Americans with Disabilities Act."

For Newton D'Souza [19], these different ways in which inclusive design is framed and presented, make it a melting point between cross paradigms: "Universal design can come under functionalist paradigm (because it caters to utility), pragmatic (because it is instrumental in nature), positivistic (because it strives for universal principles), normative (because it prescribes certain rules) and critical theorist paradigms (because it gives voice to the oppressed)." As a result, D'Souza points out, inclusive design still remains largely a-theoretical in the sense that inclusive design researchers do not explicitly affiliate themselves to any form of theoretical paradigm or other basic orientation.

\section{Question 2: How does inclusive design differ from other design approaches?}

Answer: Inclusive design shows several similarities but also major differences with other design approaches, such as design for special needs or accessible design on the one hand, and user-centred and human-centred design on the other hand.

The ambition to design to the greatest extent possible for everyone aims to differentiate inclusive design from design for special needs, which is tailored to a specific target group through 
adaptations or assistive technology. In relation to the built environment, design for special needs often focuses on wheelchair users, and is therefore often referred to as accessible or barrier-free design. Other examples of design for special needs include autism-friendly architecture (e.g., [20]), deaf space (e.g., [21]) or dementia-friendly environments (e.g., [22,23]).

Basnak et al. [9] regard accessible design as a sub-set of inclusive design, in the sense that the latter "considers all human-environment conditions, especially those that typically are overlooked". By contrast, Clarkson and Coleman [24] depict inclusive design as the inverse of earlier approaches to designing for special needs. Unlike design for disabled and older people, inclusive design no longer addresses the needs of a diverse range of users by specialised products and environments, but incorporates them in mainstream ones, assumed to benefit all. In doing so, inclusive design seeks to treat everybody in an equitable way and to avoid stigma. Coleman et al. [6] describe this distinction as a move "from margins to mainstream".

Like design for special needs, inclusive design requires in-depth insight into how particular groups of people interact with and experience the designed environment. Yet whereas design for special needs focuses on addressing the needs of these particular groups only, inclusive designs seeks resonance between their needs and the needs of the entire population $[25,26]$. Pullin and Newell [25] describe design resonance as a situation "where the needs of the people who have a particular disability coincide with particular able bodied users in particular contexts". For example, navigating sidewalks with a pram or trolley resonates with navigating them with a wheelchair - both benefit from curb cuts, i.e., sidewalks flattening into the street. Similarly, communicating in a noisy environment resembles the condition of people who are deaf or speech impaired. The latter inspired the design and innovation firm IDEO to develop TableTalk, a suite of café furniture and disposable earbuds that allows people with and without hearing impairment to comfortably have a conversation despite background noise [27]. 
Both approaches show advantages and disadvantages. Focusing on a particular group with special needs promises better tailored solutions in theory, but may cause problems for other users in reality. A classic example are the abovementioned curb cuts: important for wheelchair users and resonating with the needs of people with a pram or trolley, but causing problems for pedestrians who are vision impaired and who rely on a sharp curb to detect the edge of the sidewalk. Incorporating the needs of a particular group into the design of mainstream products and environments has the advantage that everyone is treated in an equitable way and that it avoids stigma. However, seeking resonance between special needs and the needs of the entire population is not always trivial and may require compromises (see Question 7).

Other design approaches that show similarities with inclusive design are user- and human- or people-centred design. Many research institutes that are traditionally focused on inclusive design (e.g. Institute for Human-Centered Design in Boston, The Helen Hamlyn Centre for Design in London) are using terms such as human- or people-centred design covering also inclusive design approaches. Some authors even seem to equal inclusive (or universal) design with human-centred design (e.g., [28]). Like user- and human/people-centred design, inclusive design can be understood as socially oriented or responsible design: social ends (ranging from usability to social change) are made into explicit design concerns [29]. User-centred design focuses on how people actually interact with specific products and designed environments [30]. Human- or people-centred design tends to place more emphasis on different stakeholders and broader contexts [31]. Thus, whereas user-centred design focuses mostly on micro- and meso-level interactions and relations such as ease of use or pleasurable experience (e.g., [32]), human- or people-centred design is predominantly focused on macro-level interactions and relations such as socially valued behaviours and attitudes (e.g., [33]) [29]. The main difference with inclusive design seems to be that, in addressing these interactions and relations, inclusive design starts from disabling/enabling situations in the interaction between people and the designed environment, and uses this as leverage to improve these situations for more people. 
As a result, inclusive design explicitly seeks to benefit the entire population, as will be explained in more detail below.

\subsection{Relevance and current interest}

Question 3: Why does inclusive design concern all of us?

Answer: That inclusive design concerns all of us follows from the two premises it starts from [24]:

1. "there is such considerable diversity in mental and physical capability both across the population and over the length of the life-course that the association of 'normality' with 'able-bodiedness' is neither accurate nor acceptable";

2. "disability arises from interactions with the surrounding environment that are amenable to design and structural interventions, and not inherently from capability levels, health status, or associated degrees of impairment".

The latter premise resonates with a contemporary understanding of disability referred to as the social model. Traditional conceptions consider disability as an individual physiological disorder, situated in a person's body. Accordingly, problems caused by the disorder are solved by restoring the body's function through treatment or cure. During the past decades, however, critiques of the individual and medical models placed the body in its socio-material context and stressed the role of environmental determinants in performing day-to-day activities and fulfilling social roles [34]. The social model therefore conceptually distinguishes between disability and impairment: the latter refers to a bodily dysfunction, impairment is socially constructed on top of that [35], and places the explanation of its changing character in the organisation of the society in which it is found [36], including the spaces and technologies in which this organization takes shape. As such, the social model has initiated a shift in our understanding of disability by recognizing the two-way relationship between a disabled person and his/her socio-material environment $[36,37]$. Conceiving disability not as an attribute-either of a 
person or environment-but as an effect implies a shift from static to dynamic understanding: "disabled is not something one is, but something one becomes" [38].

The premises underlying inclusive design have important implications for all of us. Regardless of whether we have an impairment or not, our physical and mental abilities will likely change in the course of our life, be it temporarily (e.g., by becoming pregnant, or breaking a leg) or permanently (e.g., by growing older). Moreover, recognizing the two-way relationship between disability and the environment implies that we all may end up in disabling situations, regardless of whether we have an impairment (see Fig. 3). Thus, Edward Steinfeld and Beth Tauke conclude, "[e]very designer should be able to design an environment that will benefit everyone, not just temporarily able-bodied people" [16].

[insert Figure 3 about here]

Moreover, more recently inclusive design has evolved towards a wider understanding of diversity beyond age and ability. Other aspects of diversity addressed in the context of inclusive design include e.g., cultural and social differences [39,40], gender [41], sexuality [42], and the intersection thereof [42]. It also becomes increasingly clear that inclusive design also has a broader relevance for healthcare and workplace design (e.g., [43]). Together these developments in understanding and addressing human diversity have progressively shifted the focus in inclusive design "from THEM - the elderly and disabled in academic parlance - to the US" [24].

\section{Question 4: Why is inclusive design of current interest?}

Answer: To start with, inclusive design is of current interest because it resonates with a growing international trend towards inclusion of disabled people into mainstream society [24]. This trend has manifested itself in different ways depending on the local circumstances, culture and social conditions. On a global scale, the Disability Rights Convention entered into force in 2008 as the first international human rights treaty specifically related to the rights of disabled people [44]. By ratifying 
the treaty, countries pledge to uphold non-discrimination and other protections and to provide disabled people with services they need to participate fully in society. The convention has been ratified by 96 countries plus the European Union. Since participation in society can be disabled or enabled by the designed environment, architects and other designers have an important role to play if these countries are to live up to the expectations they raised when ratifying the convention.

Second, inclusive design is of current interest because demographics are changing [9]. Due to both longer life expectancy in combination with declining fertility rates, the proportion of people aged over 60 is worldwide growing faster than any other age group [45]. This evolution can be considered as a success story for public health and socioeconomic development. Yet, it also challenges society to adapt in order to maximize older people's health and functional capacity as well as their social participation and security. Societal discourses on housing and care for older people reflect a growing attention for their autonomy, individuality, community integration and participation $[46,47,48,49]$, and this has important implications for built environment design. Growing older often comes with a number of changes, be it physical, cognitive, social and/or financial, which impact on our interaction with the designed environment. For instance, in later life, our vision and hearing capacity deteriorate, the risk of falling increases, and the implications of injuries are more serious. Since designed environments can either hinder, or support and stimulate people in their activities and aspirations, these changes challenge contemporary architects and other designers to take into account population ageing.

\subsection{Implications and challenges}

Question 5: What does inclusive design imply at different scales of the built environment?

Answer: Below we give some examples of how inclusive design may be relevant across different contexts and scales of the built environment. 
Several authors have pointed out that inclusively designed outdoor spaces play a key role in the engagement of older people in social life (e.g., [50],[51]). In this context, Elizabeth Burton and Lynne Mitchell introduced the concept of streets for life as a mechanism for achieving the goals of inclusive design at the neighbourhood scale and enabling outdoor environments to be as dementiafriendly as possible. To this end, they advance six key design principles - familiarity, legibility, distinctiveness, accessibility, comfort and safety.

A concept that seems to contrast with some of these principles is shared space. This traffic engineering concept, around which many spaces are being redesigned, eliminates physical barriers separating motor vehicles, pedestrians, and other road users to encourage sharing street space as a means to calm traffic and create convivial urban spaces [52]. From the perspective of inclusive design, however, this raises important challenges. According to Rob Imrie [52], shared space assumes a 'normal' body as the basis of and for negotiating shared street usage, which is likely to create disabling situations for people with a vision impairment: "It does so by reducing potentially their capacities to exercise control in those parts of the urban environment where safe space features, and means of orientation, such as kerbs and pavements, have been removed and/or merged into the general streetscape." Also for older people and people with dementia, urban spaces that are shared between pedestrians and other road users are challenging to negotiate: compared to younger adults it takes them longer to react once they have realized that it is safe to cross, and longer to cross the road [60].

At the scale of the building, the mere choice of the location already has implications for how many people are included: is there public transport in the proximity? Are there possibilities to park a car close by for people having difficulty walking? In terms of spatial organisation, the principles of universal design highlight that it is important to provide "size and space for approach and use", but also to make sure that "low physical effort" is required to enter and navigate the building, and that it allows for "simple and intuitive use" [18]. The latter relates to the logic and legibility of the spatial organisation: for instance, is it clear to people who visit the building for the first time where they are 
supposed to go, and where not? Depending on the building's function, it may also be important to allow for "flexibility in use" [18] and/or to foresee a variety of spaces. In a cancer care centre, for instance, it may be important to foresee spaces that support social interaction as well as spaces where people can retreat [53].

Including as many people as possible also has implications for multiple aspects of building comfort, such as air quality, acoustic comfort, thermal comfort, visual comfort, et cetera. In this context, it is important to keep in mind that how we experience a building is intrinsically multisensory in nature: the quality of space, matter and scale is assessed through the combination of multiple senses [54]. How a space looks is obviously important, but also how it feels, the sound and smell of a place plays a role in how people experience it. Hearing, for instance, provides auditory information about the environment, which is vital for human interaction and knowledge transfer, and essential for spatial orientation [55]. Good conditions for auditory communication require attention to the acoustic qualities of a space and, where relevant, its sound amplification system. It is especially important for people with a hearing or vision impairment, but also for the growing group of older people or when an extra language effort is needed [56]. Similarly, touching provides haptic information about the environment, whether actively, passively or dynamically [57]. Attention for haptic qualities such as textures and shapes is important to include people who rely on touch in navigating the environment, (e.g., people who are vision impaired [57]), as well as for people using a wheelchair or being wheeled in a hospital bed [58].

Building comfort and the sensory qualities of a space depend to a large extent on the materials used. For example, when designing the entrance of museum $\mathrm{M}$ in Leuven (Belgium), architect Stéphane Beel found it important that different groups of visitors do not have to separate; through the integration of a ramp in the staircase, someone using a wheelchair and someone walking can enter together by this entrance (see Fig. 4). Unfortunately, the light-coloured stone of the stairs and ramp turns out to be not ideal in sunny weather: the flight of stairs is perceived as one white 
inclined plane, which makes distinguishing the different stairs difficult. The combination with the ramp makes it even more difficult and confusing [59].

[insert Figure 4 about here]

An inclusive built environment is not a responsibility of architects and other built environment professionals only, however: disabling situations experienced in the built environment are caused not only by material barriers raised by urban spaces or buildings themselves; major problems and thus also possible solutions relate to how the built environment is used and how this use is organised. Think about people riding or parking bicycles on footways [60], the distribution of functions within a building, or even the positioning of a vending machine [61].

\section{Question 6: Why is the uptake of inclusive design limited so far?}

Answer: The uptake of inclusive design in general seems to be hampered by perceptions that it has no business case, sacrifices aesthetics, increases costs, involves a more complex design process, is not an end user need, is design for disabled people, and slows down time to market $[62,63,64]$. Furthermore, more practical barriers are identified, such as a lack of skills or tools to practice it, a lack of knowledge to assess inclusivity, competing or conflicting requirements and the client's influence or the company's culture [65].

As far as architectural design practice is concerned, the update might be hampered by the way inclusive design is understood. Interviews with professional architects indicate that they tend to associate inclusive design with the top-down framework of accessibility legislation, certificates, etc. [66]. Moreover, accessibility legislation is felt by designers as restricting their creativity and removing the challenge to come up with intelligent design solutions [37]. In a recent survey among Flemish architects, it was listed among the 10 most irritating aspects of their profession [67]. Government standardization is felt to be important, but among architects scepticism about the growing amount of rules is widespread [68]. 
Another reason for the limited uptake in architectural design practice may be that economic incentives to attend to inclusive design are perceived to be limited [66]. The arguments used in this context are often formulated with reference to people with an impairment, whose number or purchasing power is considered too limited to justify attending to their needs. This seems to suggest that architects and other built environment professionals tend to confuse inclusive design with (wheelchair) accessibility, and are unaware of its wider relevance for all of us.

Along the same line, it is felt that, as long as inclusivity - or even accessibility - is not explicitly rewarded or penalized in design competitions or commissions, there is little use in investing in it [68]. The profession as a whole does not seem to place inclusive design high on the design agenda, and that is even reflected in design awards for buildings [69].

Finally, the limited uptake may be explained by the fact that not all architecture schools have integrated inclusive design in their curriculum yet, and that those who have, often introduce it by considering the requirements of the building regulation [69]. In a survey among 88 architects (practitioners and students) who are disabled in the UK, $64 \%$ stated that they had not received any direct instruction or participated with tutors in any activities or teaching sessions designed to draw attention to inclusive design [69]. In a survey among 104 architecture schools in the US, by contrast, $69 \%$ said that inclusive design was addressed in their curriculum. However, the authors suggest that this higher-than-expected-value for incorporation may be a result of respondents mistakenly identifying accessibility curricular elements as inclusive design [9]. Moreover, of these $69 \%$, only $8 \%$ (6 schools) reported full infusion. Unlike injection-type curricular responses (e.g., incorporating a standalone UD unit into a course, devoting an entire course to UD, or offering a one-time event/workshop dedicated to UD), infusion strategies include integrating universal design materials into a subject area course, a studio problem focused on universal design, a single year of the curriculum devoted to universal design, and incorporating universal design into the entire design curriculum [70]. To our knowledge, a similar study for continental Europe does not exist. However, according to Elaine Ostroff [15], "there are only a handful of universities worldwide where universal design, or inclusive design, 
or design for all is even an elective within the professional curriculum." This seems to suggest that the situation in continental Europe is not much different than in the UK or US.

\section{Question 7: What are the challenges in inclusive design?}

Answer: A major challenge in inclusive design in general concerns the difficulty to take into account multiple perspectives. Seeking resonance between the needs of different (groups of) people may sound logical in theory, but is not always trivial in practice and may require considerable compromises. A case in point is the entrance to museum M. As mentioned, the architect tried to treat people using a wheelchair and people walking in an equitable way by integrating a ramp into the staircase. Where the ramp crosses the stairs, the banister that supports and guides people in descending the stairs stops (see Fig. 4). This is necessary for the continuation of the ramp, but for a person who is vision impaired it is difficult to find the next banister [59].

In relation to the built environment, an extra challenge relates to the fact that many spaces and buildings have been designed and built before inclusive design approaches started gaining attention. Especially in the context of built heritage, designing inclusively is not always trivial. Proposals to make historic buildings more inclusive, may raise objections from conservation authorities, which guard the historic values of built heritage.

Another major challenge relates to informing architectural design practice about the diversity of human abilities and conditions. Research suggests that architects and other designers are not per se averse to taking into account the diversity of human abilities and limitations, but that the available resources do not suit their creative process [71]. A misfit seems to exist between what is needed to design inclusively and the information formats currently available [10]. As mentioned, inclusive design requires in-depth insight into how particular groups of people interact with and experience the designed environment. For built environment professionals, the main source of information on this interaction are building codes or accessibility legislation. In this respect it is perhaps not surprising 
that inclusive design is associated with accessibility legislation. Studies show, however, that even wellconsidered legislative measurements are insufficient to ensure inclusive design $[72,73]$. Although accessibility standards derive from some kind of human consideration, they often translate accessibility into facts (or indicators and averages), e.g., by fixing maximum heights of thresholds and minimum widths of doors, which can be objectively measured. As a result, they offer built environment professionals little insight into why a particular building feature is problematic, leading to erroneous application [72]. These observations indicate a need to change how inclusivity is addressed in relation to the built environment. If designers are to understand how diverse people are affected by the built environment, qualitative dimensions are just as important as quantitative; the challenge is thus to provide information that encourages designers to go beyond minimum standards [74]. This is where user/experts have an important role to play, as we will discuss below.

\subsection{Relationship with other design issues}

Question 8: What is the role of user expertise in inclusive design?

Answer: A crucial ability for designers in general and for inclusive designers in particular, is being able to empathize with the people they design for[75]. Yet, however empathetic designers may be, they may overlook aspects that are important to people who experience space differently than they do

$[76,77]$. By consequence, user/experts have a crucial role to play in the design process. A user/expert can be anyone who has developed natural experience in dealing with the challenges of our built environment; for example, older people, people with prams or trolleys, or people living with an impairment [78], but also employees in a particular context.

Through their bodily interaction with the designed environment, user/experts can appreciate qualities designers may not be attuned to $[79,80]$. Their experience not only adds nuance to existing accessibility standards, but also offers rich insights into qualities of the built environment that surpass these standards and are important to all of us [81]: vision-impaired people mark acoustic and haptic 
qualities; those having some remaining sight pinpoint difficult lighting conditions; some people with a diagnosis on the autism spectrum are strong in identifying spaces' general atmosphere, providing insight into a building's legibility. These aspects that are crucial for user/experts may contribute to improving the overall spatial experience of all.

Moreover, user/experts may complement the existing accessibility legislation by explaining the how and why of certain requirements. In this way, user/experts may offer insight into solutions and the preconditions to alter them rather than merely apply them. These insights and the opportunity to discuss them are important to architects and other built environment professionals for whom inclusivity is but one of the aspects they seek to integrate into a coherent design.

In architectural design, involving users as experts currently is not a common practice yet. This situation can likely be improved by using methods from participatory design or co-design more commonly used in other design disciplines such as product design or service design.

\section{Question 9: How does inclusive design relate to sustainability?}

Answer: Inclusive design approaches show considerable potential to contribute to ongoing efforts to create sustainable environments. According to the most recurring literature, meeting the needs of human generations results from a balance among at least four factors: environmental sustainability, economic sustainability, social sustainability and cultural sustainability. At a basic level, designing more inclusive spaces and buildings is expected to reduce the need for adaptations in a later stage, and the environmental and economic costs thereof. In addition, social sustainability is advanced as a notion which places inclusive design under the umbrella of sustainable design (e.g., [15]). Social sustainability focuses on the development of programs, processes, and products that promote social interaction. It emphasizes protecting vulnerable people, respecting social diversity, and leveraging social capital. As such, it relates to how we make choices that affect other humans in our 'global community' [9]. This is precisely where inclusive design can contribute, without losing sight of the other dimensions of sustainability. Designing environments inclusively fosters wellbeing by starting 
from insights into what people need from the places where they live and work. Inclusive public transport and work environments, for instance, allow more people to have a job [82], which is socially and economically more sustainable. Major business potential is expected to exist in the combination of inclusive design, environmental sustainability and social responsibility [83]. By supporting people's wellbeing, health and independence, it also potentially contributes to reducing healthcare costs.

On a more general level, Leslie Kanes Weisman's [84] points out, inclusive design approaches can have a unique and powerfully positive impact on the creation of sustainable environments in at least two ways. On the one hand, inclusive design can elevate design and its value in the public consciousness. By improving the person to product or person to environment interface, it contributes to enhancing comfort, health, safety and human performance. On the other hand, Weisman argues, inclusive design fosters ethical behaviour among design professionals because it fundamentally recognizes that when designing we affect others' lives by our decisions, and that we are therefore responsible and accountable to the people who will be affected by what we do. As such, Weisman concludes, inclusive design approaches provide important guidelines to design a society in which all people and all living things matter "by recognizing the interdependence among all of humanity, the natural world and the products of human design, including the built and planned environment, and by teaching us to think, to act, and to design out of that recognition and understanding".

\subsection{Outlook}

\section{Question 10: How can inclusive design of the built environment be fostered in the future?}

Answer: A first opportunity to foster inclusive design in the future, Van der Linden et al. [10] suggest, is by shifting architects' and other designers' perception of inclusive design from accessibility towards people's spatial experiences. The present tendency to associate inclusive design with accessibility legislation inhibits a potential broader understanding of this experience, while such understanding could resonate better with architects' interests and way of working. Indeed, although many professional architects have a limited insight into inclusive design, they seem to share a common 
interest in diverse users' spatial experiences. Potential may therefore exist in demonstrating that inclusive design does not necessarily restrict the design process or reduce design solutions; on the contrary, it can mean an enrichment inspired by diverse people's spatial experiences. Creatively exploiting designers' potential can result in a plural environment [85], offering diverse spatial qualities and opportunities for using spaces in multiple ways. A case in point are the abovementioned bathing facilities designed by Carlos Mourão Pereira.

A second opportunity to foster inclusive design in the future, is by complementing the approach taken by accessibility legislation with involvement of user expertise. In architecture, user expertise in general and disability experience in particular is not yet commonly acknowledged as a valuable resource for design yet. In the exceptional cases where it is integral to the design process for example, the design of the Olympic Park for the London 2012 Olympic and Paralympic Games - it turns out to be the key to the project's success [86]. Examples like this may inspire others to involve user expertise in their projects. Very promising in this respect is the observation that design competitions start to require that participating architects demonstrate how they have involved user experience in their design proposal.

Finally, considerable potential exists in architectural education. As mentioned, the integration of inclusive design in architecture programs is limited so far. Nevertheless, the schools that have integrated it in their program, have developed various ways to sensitize students to the diversity of human abilities and limitations in relation to the built environment, which might inspire other schools. These developments range from exercises or courses (e.g., $[39,87,88,76])$ to complete dedicated postgraduate programs [89]. Promising in this respect is also the growing amount of research on inclusive design in relation to the built environment, which is expected to find its way into researchbased curricula. To inform the large number of architects and other built environment professionals that have graduated already, opportunities may also exist in integrating inclusive design in continuing professional development programs [90]. Moreover, besides through their curriculum, architecture 
schools can foster attention for diversity and inclusivity also through the composition of their faculty and teaching staff [91].

\section{$\underline{3 \text { Summary and conclusions }}$}

The limited adoption of inclusive design in design practice suggests that there are still many challenges to address, relating to the perceptions of inclusive design, its practical applicability and its infusion in architectural education. By considering ten common questions that arise when inclusive design is considered in relation to the built environment, we have attempted to contribute to dispelling the misconceptions that exist around inclusive design, and to articulating promising directions to foster more inclusive design practices in the future.

Inclusive design is a design approach of current interest that seeks to include as many people as possible. It shows major differences with e.g., design for special needs or accessible design, in the sense that it seeks to treat everybody in an equitable way by seeking resonance between the needs of people in a particular disabling situation and society at large. That it is of current interest can be understood in light of demographic changes and societal evolutions such as the growing international trend towards inclusion of disabled people into mainstream society, population ageing, and, more in general, the growing awareness of people's diversity and the increasing importance attached to participation. Inclusive design concerns all of us because it acknowledges that human abilities are diverse and change in the course of our life, and that the designed environment can be enabling or disabling for all of us. Trying to take into account as many people as possible has implications for design decisions at multiple scales of the built environment, ranging from the level of urban and landscape design to detailing and the choice of interior elements such as furniture. The premises underlying inclusive design, and the scholarly shifts in understanding it are penetrating design practice slowly. This is reflected in the perceived barriers to the adoption of inclusive design, and the related observation that architects and other built environment professionals understand inclusive design in multiple ways. Promising directions to foster inclusive design in the future include linking 
inclusivity more explicitly to architects' interest in spatial experience, for instance by complementing the approach taken by accessibility legislation with involvement of user expertise, and further integrating inclusive design in curricula of architecture and other educational programs.

Our attempt to contribute to dispelling the misconceptions around, and fostering promising directions to foster inclusive design and is limited in the sense that not all relevant references could be included in this review. References chosen were based on relevance and familiarity to us, and it is likely additional and perhaps better examples are available. Future research could investigate more systematically to what extent and in which ways inclusive design is being integrated in architectural education in continental Europe, and explore strategies to enhance infusion. In addition, we expect that much work is still needed in relation to inclusive design processes.

Awaiting the results of this future work, we expect that the body of knowledge presented in this article is relevant for built environment professionals and researchers who seek a more holistic approach to the built environment. It provides them with a basis to reflect and engage in dialogue about the human impact of design decisions. Taking into account the diversity of real people and their interactions with the built environment may provide an alternative or complement to the dominant approaches where users tend to be reduced to averages and incorporated by numbers. By offering diverse spatial qualities and opportunities for using spaces in multiple ways, inclusive design has the potential to help addressing the challenges of our diverse and ageing society in a sustainable way.

\section{Acknowledgements}

The authors acknowledge the contributions of the international community of designers and researchers who have contributed to the development of inclusive design in general, and of inclusive design in relation to the built environment in particular. Special thanks are due to the colleagues of the Research[x]Design group for their ideas and suggestions, and to the reviewers for the valuable 
feedback on the first version of the article. The authors' research received support from the Research Foundation - Flanders (FWO) and the Research Fund KU Leuven (OT/12/051 and PDM/16/091). 

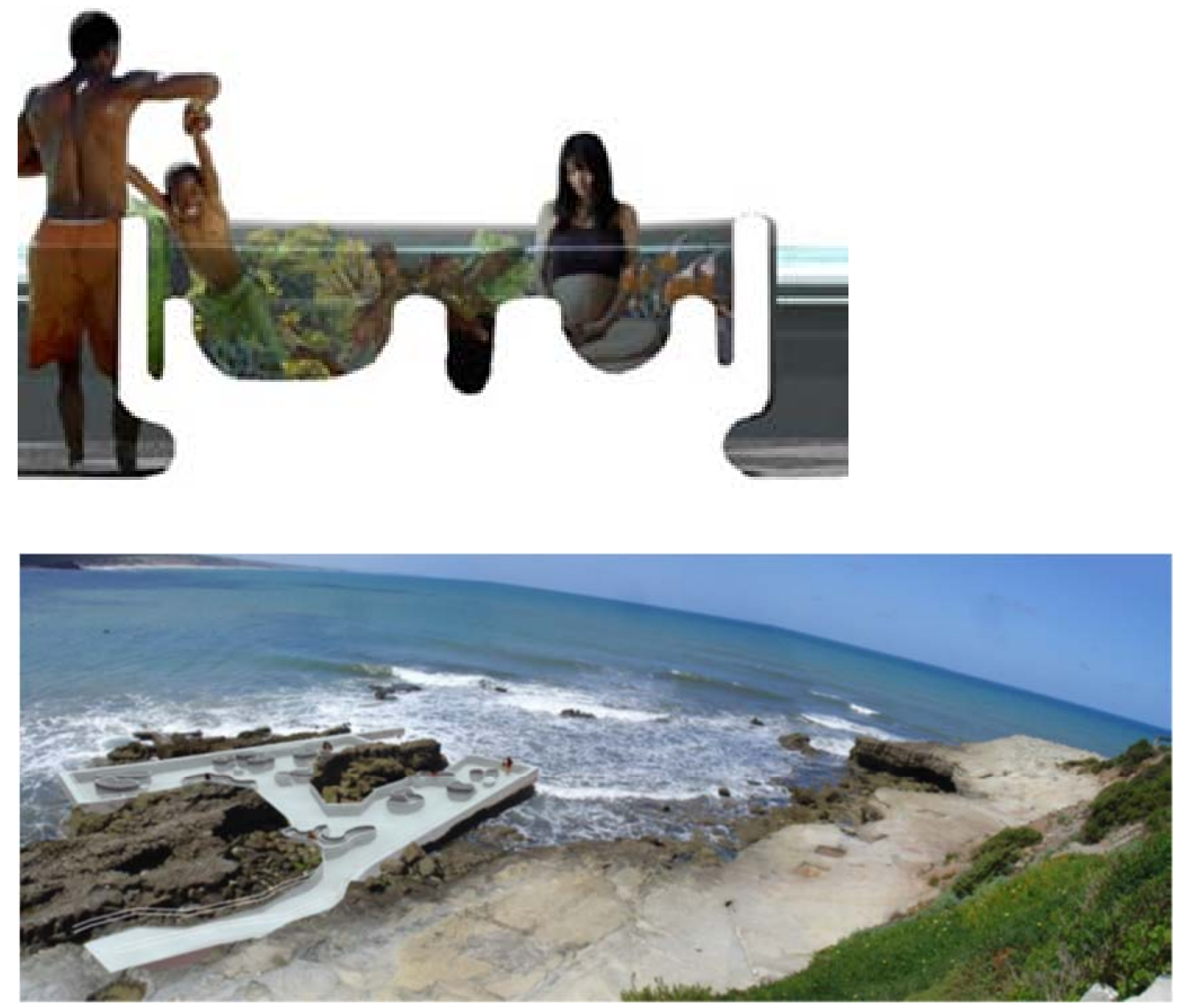

Figure 1. Sea bathing facility at the Portuguese coast, designed by Carlos Mourão Pereira. Top: section; bottom: collage; (C) Carlos Mourão Pereira 


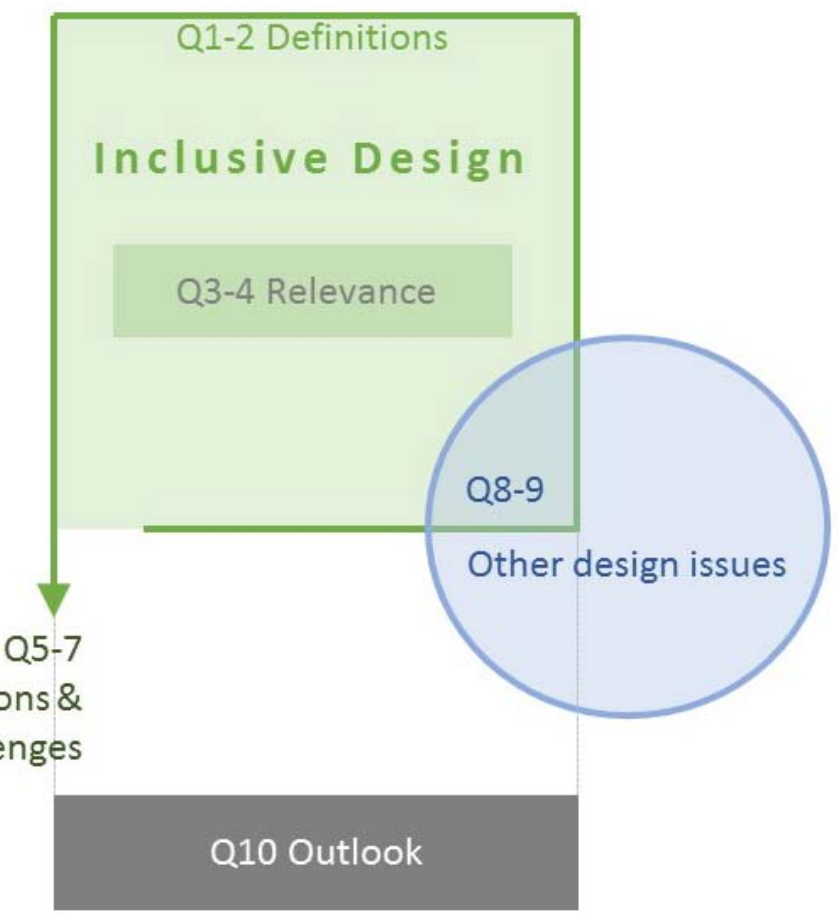

Figure 2. Overview of the themes and questions. 

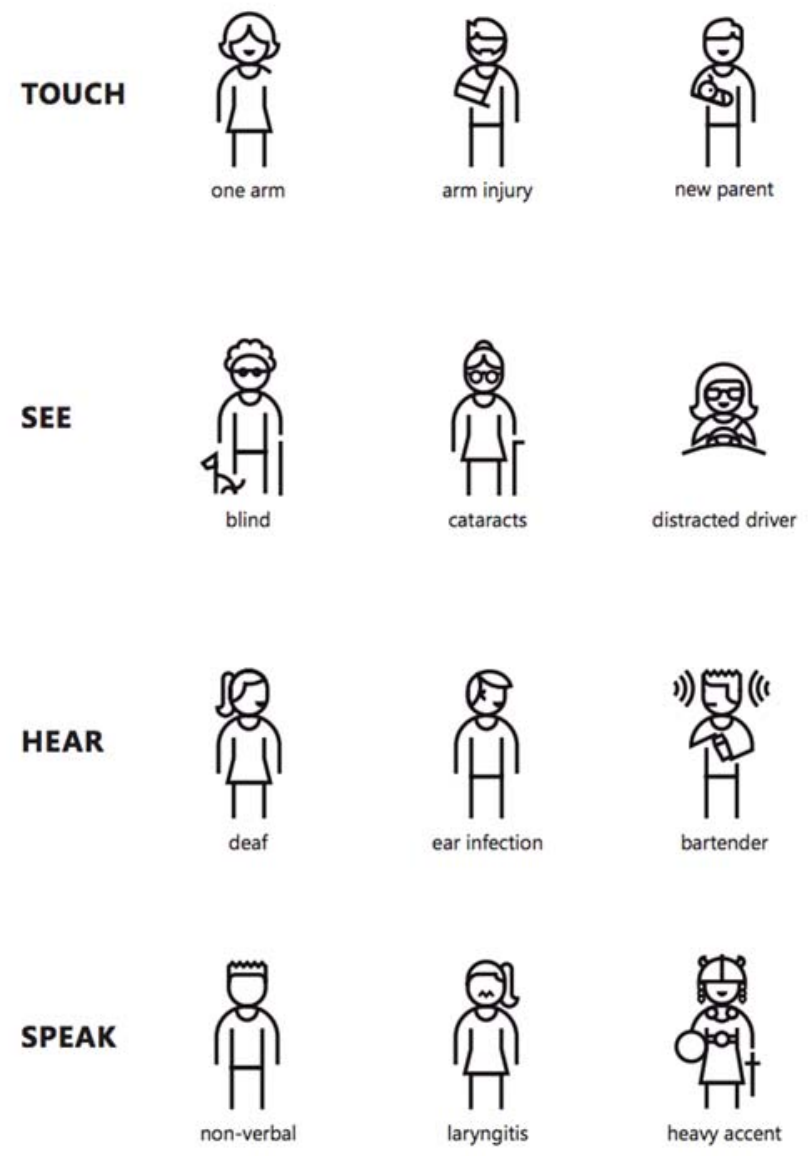

Figure 3. Examples of disabling situations. Source: Inclusive Microsoft Design [92] 


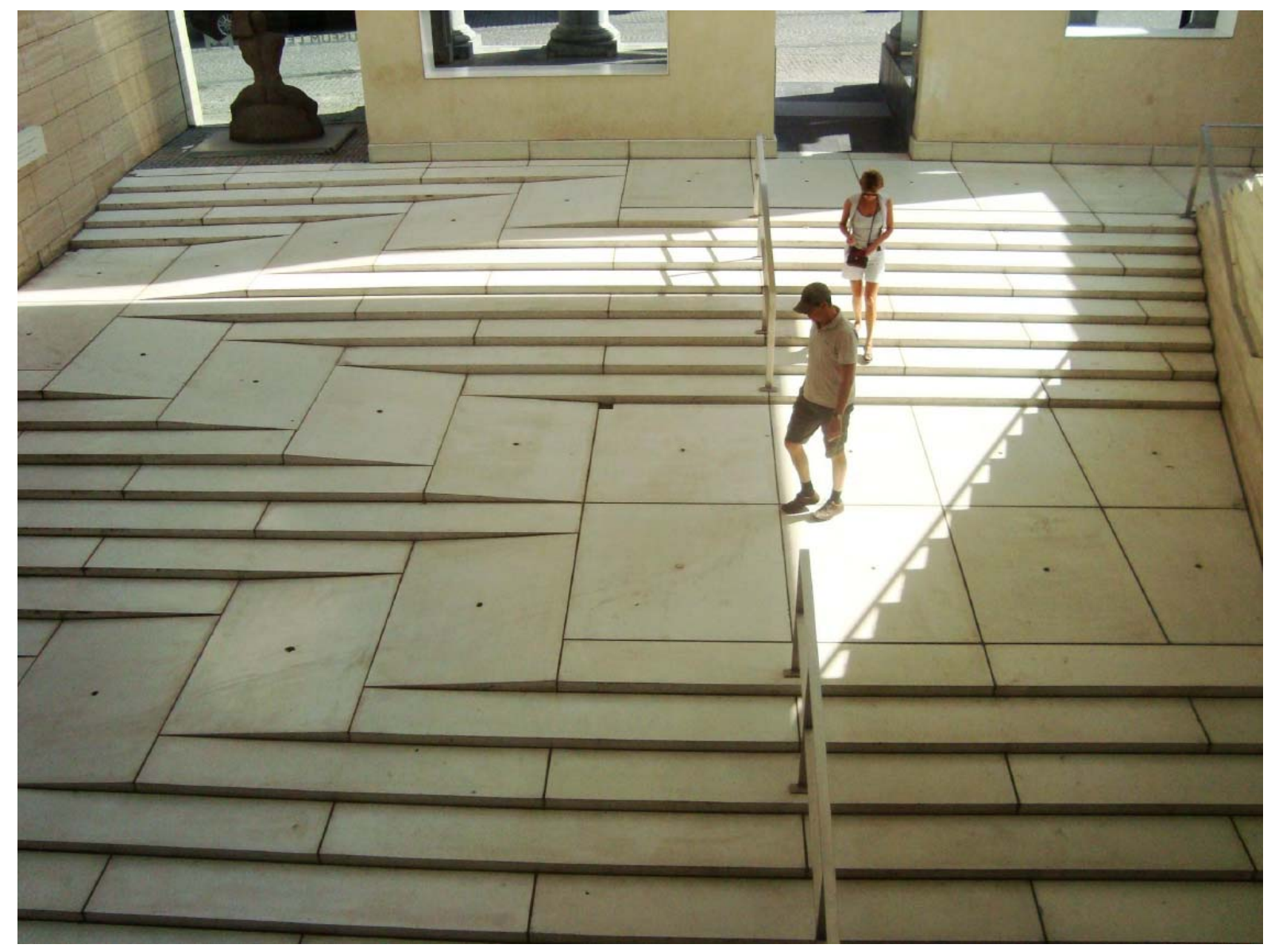

Figure 4. Entrance to museum M in Leuven (Belgium), designed by Stéphane Beel C Caroline Van Doren 


\section{References}

[1] R. Mace, Universal design: Barrier free environments for everyone, Designers West 33 (1) (1985) 147-152. Cited in: A. Hamraie, Universal Design and the Problem of "Post-Disability" Ideology, Design and Culture 2016

[2] W.F.E. Preiser, E. Ostroff (Eds.), Universal Design Handbook, McGraw-Hill, 2001.

[3] E. Steinfeld, J. Maisel, J., Universal Design: Creating inclusive environments, John Wiley \& Sons, 2012.

[4] R. Coleman, The case for inclusive design - an overview, in: Proceedings of the 12th Triennial Congress of the International Ergonomics Association, Toronto, August 15-19, 1994, International Ergonomics Association.

[5] R. Imrie, P. Hall, Inclusive Design: Designing and developing accessible environments, Spon Press, 2001.

[6] R. Coleman, C. Lebbon, P.J. Clarkson, S. Keates,. Introduction: From margins to mainstream, in: P.J. Clarkson, R. Coleman, S. Keates, C. Lebbon (Eds.), Inclusive Design: Design for the whole population, Springer, 2003, pp.1-25.

[7] EIDD Design for All Europe, Stockholm Declaration, 2004. Available at: http://www.designforalleurope.org/Design-for-All/EIDD-Documents/Stockholm-Declaration/

[8] P. Vermeersch, A. Heylighen, Rendering the tacit observable in the learning process of a changing body, in N. Nimkulrat, K. Niedderer, M. Evans (Eds.), Knowing Inside Out - experiential knowledge, expertise and connoisseurship. EKSIG 2013. Loughborough, July 4-5, 2013, Loughborough University, pp. 259-270.

[9] M. Basnak, B. Tauke, S. Weidemann, Universal Design in Architectural Education: Who is Doing It? How is It Being Done?, in: A. Aksamija, J. Haymaker, A. Aminmansour (Eds.), Future of Architectural Research. Proceedings of the Architectural Research Centers Consortium ARCC 2015 Conference, Perkins+Will, 2015, pp.670-678. 
[10] V. Van der Linden, H. Dong, A. Heylighen, From accessibility to experience: Opportunities for inclusive design in architectural practice. Nordic Journal of Architectural Research 28(2) 201633 58.

[11] A. Heylighen, About the nature of design in universal design, Disability and Rehabilitation 36(16) 2014 1360-1368.

[12] H. Wauters, P.W. Vermeersch, A. Heylighen, Reality check: Notions of accessibility in today's architectural design practice, in: Y.-K. Lim, K. Niedderer, J. Redström, E. Stolterman, A. Valtonen (Eds.), DRS 2014: Design's Big Debates. Umeå, June 16-19, 2014., Design Research Society \& Umeå Institute of Design, pp.1482-1491.

[13] National Disability Authority, UN Convention on the Rights of Persons with Disabilities and Council of Europe DisabilityActionPlan, undated. Cited in: E. Ostroff, Universal Design: An Evolving Paradigm, Universal design handbook, 2nd ed. McGraw-Hill, 2011, pp.1.3-1-11.

[14] Design Council, 2008. Inclusive Design Education Resource. Design Council, London, UK, 2008. http://www.designcouncil.info/inclusivedesignresource/. Cited in: P.J. Clarkson, R. Coleman, History of inclusive design in the UK, Applied Ergonomics, 46 (Part B) 2015 235-247.

[15 ] E. Ostroff, Universal Design: An Evolving Paradigm, Universal design handbook, 2nd ed. McGrawHill, 2011, pp.1.3-1-11.

[16] E. Steinfeld, B. Tauke, Universal designing, in: J. Christophersen (Ed.), Universal design. 17 ways of thinking and teaching, Husbanken, 2002, pp. 165-89.

[17] R. Duncan, Universal design - clarification and development. A Report for the Ministry of the Environment, Government of Norway, North Carolina State University, Center for Universal Design, 2007.

[18] B.R. Connell, M. Jones, R. Mace, J. Mueller, A. Mullick, E. Ostroff, J. Sanford, E. Steinfeld, M. Story, G. Vanderheiden, The Principles of Universal Design. Raleigh (NC): NC State University, Center for Universal Design, College of Design, 1997. Available at: 
[19] N. D'Souza, Is universal design a critical theory?, in: S. Keates, P.J. Clarkson, P. Langdon, P. Robinson (Eds.), Designing a more inclusive world, Springer-Verlag, 2004, pp. 3-10.

[20] M. Mostafa, Housing adaption for Adults with Autistic Spectrum Disorder, Open house international 35(1) 2010 37-48.

[21] C. Edwards, G Harold, DeafSpace and the principles of universal design, Disability and Rehabilitation 36(14) 2014 1350-1359.

[22] G. Marquardt, P. Schmieg, (2009) Dementia-friendly architecture, American Journal of Alzheimer's Disease and other Dementias 24(4) 2009 333-340.

[23] L. Mitchell, E. Burton, Neighbourhoods for life: Designing dementia-friendly outdoor environments, Quality in Ageing and Older Adults 7(1) 2006 26-33.

[24] P.J. Clarkson, R. Coleman, History of inclusive design in the UK, Applied Ergonomics, 46(Part B) $2015235-247$.

[25] G. Pullin, G., A.F. Newell, Focusing on extra-ordinary users, Universal Acess in Human Computer Interaction. Lecture Notes in Computer Science 45542007 253-262.

[26] C. Andrews, Embracing resonance. A case study, in: P. Langdon, J. Lazar, A. Heylighen, H. Dong (Eds.), Inclusive Designing. Joining Usability, Accessibility and Inclusion, Springer, 2014, pp. 211222.

[27] IDEO, Hearwear - Tabletop concept project, 2007. Available at: https://vimeo.com/3563281

[28] H. Froyen, Universal Design. A methodological approach. A pathway to human-friendly and elegant architecture. IHCD, Boston, 2012.

[29] L. Stam, Social engagement in design: A new perspective. Unpublished master thesis, 2015.

[30] A. Willis, User-Centred Design, Design Philosophy Papers 2(1) 2004 1-5.

[31] T. Zhang, H. Dong, (2008) Human-centred design: an emergent conceptual model, in: Proceedings of Include2009, Royal College of Art, London, April 8-10, 2009. Available at: http://www.hhc.rca.ac.uk/2084/all/1/proceedings.aspx

[32] H.N.J. Schifferstein, P. Hekkert (Eds.), Product experience. Elsevier, 2008. 
[33] N. Tromp, P. Hekkert, P.P Verbeek, Design for socially responsible behavior: A classification based on intended user experience, Design Issues 27(3) 2011 3-19.

[34] P. Fougeyrollas, Documenting environmental factors for preventing the handicap creation process: Quebec contributions relating to ICIDH and social participation of people with functional differences. Disability and Rehabilitation 17(3-4) 1995 145-153.

[35] M. Corker, T. Shakespeare, Mapping the terrain, in: M. Corker, T. Shakespeare (Eds.), Disability/Postmodernity: Embodying Disability Theory, Bloomsbury Academic, 2002, pp. 1-17.

[36] R. Butler, S. Bowlby, Bodies and spaces: an exploration of disabled people's experiences of public space, Environmental and Planning D: Society and Space 151997 441-433.

[37] D.B. Gray, M. Gould, J.E. Bickenbach, Environmental barriers and disability. Journal of Architectural and Planning Research 20(1) 2003 29-37.

[38] I. Moser, On becoming disabled and articulating alternatives, Cultural Studies 19(6) 2005 667700.

[39] A. Pedersen, C. Crouch, Introducing Universal Design to a Colonial Context, in: J. Christophersen (Ed.), Universal Design, Norwegian State Housing Bank, 2002, pp. 289-314.

[40] N. St John, Towards more culturally inclusive communication design practices: exploring creative participation between non-Indigenous and Indigenous people in Australia, In: Proceedings of DRS 2016, Design Research Society 50th Anniversary Conference, Brighton, UK, June 27-30, 2016.

[41] T.S. Goldhaber, P. Langdon, P.J. Clarkson, Gender Issues in ICT Adoption: A Literature Review. In: P. Langdon, J. Lazar, A. Heylighen, H. Dong (Eds.), Inclusive Designing. Joining Usability, Accessibility and Inclusion, Springer, 2014, pp. 59-68.

[42] R. Skjerve, G.A. Giannoumis, S. Naseem, An Intersectional Perspective on Web Accessibility, in: P. Langdon, J. Lazar, A. Heylighen, H. Dong (Eds.), Designing Around People, Springer, 2016, pp.1322. 
[43] T. Horberry, T. Cooke 2012. Safe and inclusive design of equipment used in the minerals industry. In P. Langdon, J. Clarkson, P. Robinson, J. Lazar, A. Heylighen (Eds.), Designing inclusive systems: Designing inclusion for real-world applications, Springer-Verlag, pp. 23-32.

[44] UN, Convention on the Rights of Persons with Disabilities. Available from http://www.un.org/disabilities/convention/conventionfull.shtml

[45] WHO, Ageing. Available from: http://www.who.int/topics/ageing/en/

[46] A. Declercq, De complexe zoektocht tussen orde en chaos. Een sociologische studie naar de differentiatie in de institutionele zorgregimes voor dementerende ouderen. [The complex search between order and chaos. A sociological study of the differentiation in the institutional care regimes for older people with dementia]. PhD Dissertation. KU Leuven, 2000.

[47] N. Mens, C. Wagenaar, De architectuur van de ouderenhuisvesting: bouwen voor wonen en zorg, NAi Uitgevers, 2009.

[48] M. Elf, P. Fröst, G. Lindahl, H. Wijk, Shared decision making in designing new healthcare environments -time to begin improving quality. BMC Health Services Research, 15 (1) 2015 art.nr. 114.

[49] C. Van der Kooij, Van oude mensen vroeger en nu: over de geschiedenis van de ouderdom en de zorg voor oude mensen [About older people then and now; about the history of old age and the care for older people]. Van Loghum Slaterus, 1987.

[50] E. Burton, L. Mitchell, Inclusive Urban Design: Streets for Life. Architectural Press, 2006.

[51] Y. Afacan, Elderly-Friendly Inclusive Urban Environments: Learning From Ankara, Open House International 38(1) 2013 52-62.

[52] R. Imrie, Auto-disabilities: The Case of Shared Space Environments, Environment and Planning A 44(9) $20122260-2277$.

[53] V. Van der Linden, M. Annemans, A. Heylighen, Architects' approaches to healing environment in designing a Maggie's Cancer Caring Centre, The Design Journal 19(3) 2016 511-533.

[54] J. Pallasmaa, The eyes of the skin, John Wiley \& Sons, 2005. 
[55] M Rychtárikova', M. Van den Bogaert, G. Vermeir, J. Wouters, Localisation of the speaker in a real and virtual reverberantroom, NAG-J., J. Acoust. Soc. Neth. 184(8) 2007 (CD-Rom).

[56] A. Heylighen, M. Rychtarikova, G. Vermeir, Designing Spaces for Every Listener, Universal Access in the Information Society 9(3) $2010283-292$.

[57] J. Herssens, Designing Architecture for More: A Framework of Haptic Design Parameters with the Experience of People Born Blind, PhD Dissertation, UHasselt \& KU Leuven, 2011.

[58] A. Annemans, The Experience of Lying: Informing the design of hospital architecture on patients' spatial experience in motion, PhD dissertation. KU Leuven, 2015.

[59] A. Heylighen, C. Van Doren, P. Vermeersch, Enriching our understanding of architecture through disability experience, Open House International 38(1) 2013 7-19.

[60]

[61] A. Heylighen, Inclusive Built Heritage as a Matter of Concern: A Field Experiment, in: P. Langdon, P. Clarkson, P. Robinson, J. Lazar, A. Heylighen (Eds.), Designing Inclusive Systems, SpringerVerlag, 2012, pp. 207-216.

[62] G. Vanderheiden, J. Tobias, Universal design of consumer products: Current industry practice and perceptions, Proceedings of the Human Factors and Ergonomics Society Annual Meeting 44(32) 2000 19-22.

[63] H. Dong, P.J. Clarkson, S. Ahmed, S. Keates, Investigating perceptions of manufacturers and retailers to inclusive design, The Design Journal 7(3) 2004 3-15.

[64] J. Goodman, H. Dong, P. Langdon, P.J. Clarkson, Increasing the uptake of inclusive design in industry, Gerontechnology 5(3) 2006 140-149.

[65] J. Goodman-Deane, P. Langdon, P.J. Clarkson, Key influences on the user-centred design process, Journal of Engineering Design 21(2-3) 2010 345-373.

[66] A. Heylighen, J. Schijlen, V. Van der Linden, D. Meulenijzer, P.W. Vermeersch, Socially Innovating Architectural Design Practice by Mobilising Disability Experience. An Exploratory Study, Architectural Engineering and Design Management 12(4) 2006 253-265. 
[67] NAV, Ons vak in vorm: Het eerste architectencongres [Our profession in shape: The first architects congress]. NAV, de Vlaamse Architectenorganisatie, 2012.

[68] P. De Cauwer, M. Clement, H. Buelens, A. Heylighen, Four reasons not to teach inclusive design. Proceedings of Include 2009, Royal College of Art, Helen Hamlyn Centre, 2009.

[69] S. Manley, A. de Graft-Johnson, K. Lucking, Disabled architects: unlocking the potential for practice, RIBA \& Univ. of West England, 2011.

[70] P. Welch, S. Jones. 2001. Advances in universal design education in the United States, Universal design handbook, 2001, pp. 51.1-51.24.

[71] A. Bruseberg, D. McDonagh-Philp, Focus groups to support the industrial/product designer: A review based on current literature and designers' feedback, Applied Ergonomics 33(1) 2002 2738.

[72] J.M. Franz, G. Bitner, N. Wright, C. Gillett, R. Hannaford, Inclusive universal design practice and activism: A case study, in: M. Narikawa (Ed.), Proceedings of the 3rd International Conference: Universal Design, International Association for Universal Design, 2010.

[73] M. lantkow, Inclusive Design Education of Environmental Designers: A Transdisciplinary Approach, Doctoral dissertation, Calgary: University of Calgary, 2015.

[74] M.G. Ormerod, R.A. Newton, Moving Beyond Accessibility: The Principles of Universal (inclusive) Design as a Dimension in nD Modelling of the Built Environment, Architectural Engineering and Design Management 1(2) 2005 103-110.

[75] K. Dorst, Understanding Design: 150 reflections on being a designer, 2nd ed., BIS Publishers, 2006.

[76] A. Heylighen, P.W. Vermeersch, Mobilizing disability experience to inform architectural education. Lessons learned from a field experiment, Raising Awareness for the Societal and Environmental Role of Engineering and (Re)Training Engineers for Participatory Design, Engineering 4 Society, Leuven, June 18-19, 2015, IEEE, pp. 51-58. 
[77] N. Crilly, A. Maier, P.J. Clarkson, Representing artefacts as media, International Journal of Design 2(3) 2008 15-27.

[78] E. Ostroff, Mining our natural resources: The user as expert, INNOVATION 16(1) 1997 33-35.

[79] J. Cassim, H. Dong, Critical users in design innovation, in: J. Clarkson, S. Keates, R. Coleman, C. Lebbon (Eds.), Inclusive Design: Design for the whole population, Springer, 2003, pp. 532-53.

[80] G. Pullin, Design meets disability, MIT Press, 2009.

[81] P.W. Vermeersch, A. Heylighen, Mobilizing disability experience to inform architectural practice. Lessons learned from a field study, Journal of Research Practice 11(2) 2015 art.nr. M3.

[82] M. Kulkarni, K.V. Gopakumar, Career management strategies of people with disabilities, Human Resource Management 53(3) 2014 445-466.

[83] K. Bendixen, M. Benktzon, Design for All in Scandinavia - A strong concept, Applied Ergonomics 46(Part B) 2015 248-257.

[84] L. K. Weisman, Creating the universally designed city: Prospects for the New Century, Architectural Theory Review 5(2) 2000 156-173.

[85] M. Winance, Universal design and the challenge of diversity: Reflections on the principles of UD, based on empirical research of people's mobility, Disability and Rehabilitation 36(16) 20141334 1343.

[86] J. Fleck, Inclusive design -a lasting Paralympic Legacy? Embedding inclusive design knowledge and skills into architectural education, Charette 2(1) 2015 92-105.

[87] Z. Ceresnova, Student engagement in assessment of universal access of university buildings, in: P. Langdon, J. Lazar, A. Heylighen, H. Dong (Eds.), Inclusive Designing. Joining Usability, Accessibility and Inclusion, Springer, 2014, pp. 143-152.

[88] M. Dujardin, Learning from practice: Post-Occupancy Evaluation (POE) as a UD teaching tool at Sint-Lucas Architecture, Belgium, Proceedings of Include 2011, Royal College of Art, Helen Hamlyn Centre, 2011. 
[89] C. Ryhl, A.K. Frandsen, A New Professional Master in Universal Design in the Built Environment, Nordic Journal of Architectural Research 28(2) 2016.

[90] E.C.O. Shea, M. Basnak, M. Bucholz, E. Steinfeld, Universal Design and Continuing Professional Development for Architects: An Irish Case Study, in: H. Petrie et al. (Eds.), Universal Design 2016: Learning from the Past, Designing for the Future, IOS Press, 2016, pp. 189-198.

[91] K. H. Anthony, Designing for Diversity: Implications for Architectural Education in the Twenty-first Century, Journal of Architectural Education 55(4) 2002 257-267.

[92] A. Shum, K. Holmes, K. Woolery, M. Price, D. Kim, E. Dvorkina, D. Dietrich-Muller, N. Kile, S. Morris, J. Chou, S. Malekzadeh, Inclusive Microsoft Design, 2016. Available at: $\underline{\text { www.microsoft.com/design/inclusive }}$ 